\title{
Hepatitis $C$ virus induces oxidative stress and DNA damage by regulating DNAPKCs, ATM, ATR and PARP mediated signaling and guards cell from cancerous condition by upregulating RB, P53 and downregulating VEGF
}

\author{
U. SAEED, Z. Z. PIRACHA, S. MANZOOR*
}

\author{
${ }^{1}$ Atta- ur-Rahman School of Applied Biosciences (ASAB), National University of Sciences and Technology (NUST), H-12 Sector \\ Islamabad (44000), Pakistan
}

Received July 21, 2016; revised November 16, 2016; accepted June 30, 2017

\begin{abstract}
Summary. - Hepatitis C virus is responsible for liver damage and various metabolic disorders. HCV infections promote oxidative stress and cause damage to macromolecules. The aim of our study was to design a preliminary study with establishment of HCV genotype 3a infectivity assay in order to determine DNA damage in Huh-7 cell line at 72 hours post inoculation. Quantitative expression levels of COX-2 and GSR (oxidants and antioxidants), DNAPKCs, ATM, ATR and PARP (DNA damage and repair genes), RB and P53 (tumor suppressor genes) and VEGF (angiogenesis marker) were observed via real time PCR. Our findings revealed 1.533 fold upregulated expression of COX-2. The expression level of GSR was increased by 1.27 fold and VEGF expression decreased by 0.367 fold. Thus, preventing cells to enter cancerous phase.
\end{abstract}

Keywords: hepatitis C virus; DNA damage and repair; cyclooxygenase-2; glutathione reductase; DNAPKCs; VEGF; P53; RB

\section{Introduction}

Hepatitis $\mathrm{C}$ virus (HCV) is blood borne pathogen which causes severe liver disorders, including hepatocellular carcinoma (HCC), hepatic steatosis, liver cirrhosis, end stage liver disease and various metabolic disorders (Saeed et al., 2014, 2015). In 1975 hepatitis C virus (HCV) was initially recognized as non-A, non-B viral hepatitis (NANBH). The newly discovered flavi-like virus was responsible for transfusion associated hepatitis (Houghton 2009; Feinstone et al., 1975; Alter et al., 1975). WHO statistical analysis revealed liver cirrhosis as 18th most common cause of mortality and it is estimated to achieve

*Corresponding author: E-mail: lcianunique@yahoo.com; dr.sobiamanzoor@asab.nust.edu.pk; phone:+92-51-9085-6147.

Abbreviations: ATM = ataxia-telangiectasia mutated; ATR = ataxia telangiectasia and Rad3-related protein; COX-2 = cyclooxygenase-2; DNAPKC = DNA-dependent protein kinase, catalytic subunit; GSR = glutathione reductase; $\mathrm{HCC}=$ hepatocellular carcinoma; $\mathrm{PARP}=$ poly (ADPribose) polymerase; $\mathrm{P} 53=$ tumor protein $\mathrm{p} 53$; $\mathrm{RB}=$ retinoblastoma protein gene; $\mathrm{ROS}$ = reactive oxygen species; VEGF $=$ vascular endothelial growth factor 13th position by 2030 (WHO World Health Statistics Geneva, 2008). HCV induced oxidative stress is one of the contributing factors of DNA damage leading towards HCC. The increased generation of reactive oxygen and nitrogen species, together with the decreased antioxidant defense promotes DNA damage and reduces DNA repair mechanisms. Oxidative stress is a state of disequilibrium in levels of oxidants and antioxidants. It involves building of highly reactive oxygen species and free radicals in human body which causes development of detrimental effects such as liver damage. Reactive oxygen species (ROS) include nitric oxide, hydrogen peroxide, superoxide, peroxynitrite, hydroxyl radical and hypochlorite (Sies, 1997). Oxidative damage is also potent contributing factor of steatosis, fibrosis and hepatocellular carcinoma. However, during normal metabolic processes occurring in human body some of the atoms and molecules acquire extra electron and become free radicals. Due to the presence of unpaired electron in outer shell, these radicals make bonds with other molecules thereby stealing electrons from other molecules and establishing chemical chain reactions. Under physiological stress: such as chronic infection, pollution, radiation and consumption of 
high fat diet; the process of free radical production increases. Mitochondrial impairment causes increase in production of free radicals. The oxidative stress occurs in human body after the overproduction of free radical production compared to the defensive natural antioxidants. The presence of free oxygen radicals tends to alter cellular structures and processes after disrupting proteins and fats. The oxidative stress causes not only damage to cellular membranes but also macromolecules such as DNA. DNA damage and repair system of humans, if disrupted by oxidative stress, may lead towards mutation in genetic code. The existence of such phenomenon may lead towards inappropriate cytokine production, disturbed signaling pathways which affect apoptosis, cancer, neurodegenerative diseases, atherosclerosis and overall aging process (Highleyman, 2008; Choi and Ou, 2006; Koike, 2007). Presence of ROS is not always detrimental as it plays vital role in accumulating platelet molecules towards the site of injury and activating strong immune responses against pathogens. HCV itself promotes oxidative stress in liver cells and this phenomenon is amplified in patients with $\mathrm{HCV} / \mathrm{HIV}$ co-infection. How $\mathrm{HCV}$ induces oxidative stress is not fully understood and this phenomenon is still under research. It has been reported that HCV proteins enhance oxidative stress in hepatocytes, while interestingly HBV does not seems to have similar kind of action (Highleyman, 2008).

Oxidative stress is responsible for liver disease progression towards both steatosis and fibrosis. Oxidative stress enhances lipid per-oxidation; during which free radicals quench electrons out of fat molecules and cause its break down. The byproducts produced as a result of fat breakdown contribute to liver steatosis. Similarly, free radicals along with lipid per-oxidation byproducts are also responsible for the release of pro-inflammatory cytokines. This phenomenon encourages hepatic stellate cell activity which ultimately leads towards fibrosis (Mantena et al., 2008; Vidali et al., 2008). $\mathrm{HCV}$ induced chronic inflammation and generation of ROS oxidants with decreased antioxidant defense promotes DNA damage and increases chromosomal aberrations implicated in development of HCV associated HCC (Maki et al., 2007). Few studies have revealed that prostaglandin-endoperoxide synthase (PTGS) also known as cyclooxygenase-2 (COX-2) expression is correlated with vascular endothelial growth factor (VEGF) expression in HCC. Oxidative stress may participate in the development of hepatic steatosis and its progression to fibrosis in the hepatitis $\mathrm{C}$ patients. Current study involves establishment of HCV infected Huh-7 cell line and evaluating the mRNA expression of glutathione reductase (GSR), COX-2, retinoblastoma protein (RB), poly (ADPribose) polymerase (PARP) and VEGF. P53 has been shown to play a pivotal role in DNA damage repair pathways, including double strand breaks (DSBs), single strand breaks, base excision and mismatch repairs (Jalal et al., 2014). We hypothesized that HCV causes the oxidative stress, which in turn leads towards DNA damage (detected by DNA damage and repair genes ATM, ATR, DNAPKCs, PARP) and influences the expression of genes involved in carcinogenesis. Huh 7 cell line transfected with HCV strains of genotype 3a were used to quantify the expression levels of cellular genes e.g., oxidants (COX-2), antioxidants (GSR), DNA damage and repair genes (ATM, ATR, DNA PKCs), tumor suppressor genes (P53 and RB) and the genes involved in angiogenesis (VEGF). We have also established in vitro HCV infected cell line model, by infecting cell lines with a particular HCV genotype and identified variation in expression levels of GSR, COX-2, RB, PARP and VEGF.

\section{Materials and Methods}

Primer design. Primers were designed in Primer3 Version 0.40 for the real time PCR quantification of gene expression of the selected markers. The mRNA sequences of the selected markers were obtained from NCBI gene bank and blast analysis was performed in order to confirm the genome specificity. All of the gene specific primers were used for transcriptional analysis.

Samples. The serum samples of chronically infected HCV genotype 3a patients were obtained from Atta ur Rahman School of Applied Biosciences (ASAB) Diagnostic Laboratory, National University of Sciences and Technology (NUST) Islamabad, Pakistan. The collected serum samples were subjected to real time quantification and genotype testing by ASAB diagnostic laboratory. Patient titer ranged from 100,000 to 3,500,000 IU/ml. Patient written consent and approval was obtained from institutional ethics committee.

Cells and HCV infection. The Huh-7 cells were grown in cell culture flasks (Corning, USA) containing Dulbecco's Modified Eagle's Medium DMEM (Sigma Aldrich, USA) supplemented with $10 \%$ fetal bovine serum (FBS) and containing $100 \mu \mathrm{g} / \mathrm{ml}$ penicillin, $100 \mu \mathrm{g} / \mathrm{ml}$ streptomycin antibiotics. Cells were grown in strictly sterile environment of cell culture incubator (Sanyo, South Korea) at $37^{\circ} \mathrm{C}$ with humidified environment and $5 \% \mathrm{CO}_{2}$. Confluent Huh-7 cells were trypsinized with 1x trypsin (Sigma Aldrich, USA). $1 \times 10^{\wedge} 5-1.5 \times 10^{\wedge} 5$ cells from cell suspension having $98-100 \%$ viability were plated in $60 \mathrm{~mm}$ tissue culture plates and inoculated with HCV positive sera at confluency of $30-45 \%$. Huh-7 cell line was used to establish transient in vitro replication of HCV. The Huh-7 maintained in $60 \mathrm{~mm}$ tissue culture plates up to $30-35 \%$ confluency were washed with $1 \mathrm{x}$ phosphate buffer saline PBS (Sigma Aldrich) and then inoculated with HCV positive sera in 1:2 ratio of cells to infectivity units. In order to inoculate cells in a cell to infectivity units ratio of 1:2, appropriate amount of serum was mixed in $3 \mathrm{ml}$ of complete media and added to the cell culture. Cells inoculated with HCV positive sera were maintained overnight at $37^{\circ} \mathrm{C}$ in $5 \% \mathrm{CO}_{2}$. At 24 hours post inoculation, HCV serum containing media was removed, adherent cells were washed thrice with 1x PBS. Washed cells were replenished with 
Table 1. Sequences of forward (F) and reverse (R) primers and PCR conditions

\begin{tabular}{|c|c|c|}
\hline Gene & Primer sequence & PCR conditions \\
\hline ATR & $\begin{array}{l}\text { F: 5' CCGCAAAAGGA } \\
\text { GATTTGGTA 3' } \\
\text { R: 5' TTCGGAAGTGCTGT } \\
\text { CATCTG 3' }\end{array}$ & $\begin{array}{l}35 \text { cycles }\left(45 \text { s } 95^{\circ} \mathrm{C}, 45\right. \\
\text { s } 59^{\circ} \mathrm{C}, 45 \text { s } 72^{\circ} \mathrm{C}, 10 \mathrm{~min} \\
\left.72^{\circ} \mathrm{C}\right)\end{array}$ \\
\hline PARP & $\begin{array}{l}\text { F: 5' GCTCCTGAACAAT } \\
\text { GCAGACA 3' } \\
\text { R: 5' CATTGTGTGTGGTT } \\
\text { GCATGA 3' }\end{array}$ & $\begin{array}{l}35 \text { cycles }\left(45 \text { s } 95^{\circ} \mathrm{C}, 45\right. \\
\text { s } 59^{\circ} \mathrm{C}, 45 \text { s } 72^{\circ} \mathrm{C}, 10 \mathrm{~min} \\
\left.72^{\circ} \mathrm{C}\right)\end{array}$ \\
\hline RB & $\begin{array}{l}\text { F: 5' TTCACCCT TACG } \\
\text { GATTCCTG 3' } \\
\text { R: 5' GGTTTAGGAGGGTT } \\
\text { GCTTCC 3' }\end{array}$ & $\begin{array}{l}35 \text { cycles }\left(45 \text { s } 95^{\circ} \mathrm{C}, 45\right. \\
\text { s } 59^{\circ} \mathrm{C}, 45 \text { s } 72^{\circ} \mathrm{C}, 10 \mathrm{~min} \\
\left.72^{\circ} \mathrm{C}\right)\end{array}$ \\
\hline P53 & $\begin{array}{l}\text { F: 5' GTCTGGGCTTCTT } \\
\text { GCATTCT 3' } \\
\text { R: 5' CTCCGTCATGTGCT } \\
\text { GTGACT 3' }\end{array}$ & $\begin{array}{l}35 \text { cycles }\left(40 \text { s } 95^{\circ} \mathrm{C}, 40\right. \\
\text { s } 60^{\circ} \mathrm{C}, 40 \text { s } 72^{\circ} \mathrm{C}, 10 \mathrm{~min} \\
\left.72^{\circ} \mathrm{C}\right)\end{array}$ \\
\hline DNA PKCs & $\begin{array}{l}\text { F: 5' CT T TGTCGTGT } \\
\text { GGAGGGAAT 3' } \\
\text { R: 5' CACAACGGGGTTCA } \\
\text { GAAGTT 3' }\end{array}$ & $\begin{array}{l}35 \text { cycles }\left(45 \text { s } 95^{\circ} \mathrm{C}, 45\right. \\
\text { s } 60^{\circ} \mathrm{C}, 45 \text { s } 72^{\circ} \mathrm{C}, 10 \mathrm{~min} \\
\left.72^{\circ} \mathrm{C}\right)\end{array}$ \\
\hline ATM & $\begin{array}{l}\text { F: 5' T TAAGGTGGAC } \\
\text { CACACAGGAG 3' } \\
\text { R: } 5{ }^{\prime} \text { GCAT G A C A G } \\
\text { CATCTTGTCTCA 3' }\end{array}$ & $\begin{array}{l}35 \text { cycles }\left(45 \text { s } 95^{\circ} \mathrm{C}, 45\right. \\
\text { s } 58^{\circ} \mathrm{C}, 45 \text { s } 72^{\circ} \mathrm{C}, 10 \mathrm{~min} \\
\left.72^{\circ} \mathrm{C}\right)\end{array}$ \\
\hline COX-2 & $\begin{array}{l}\text { F: 5' TGCTGTGGAGCTG } \\
\text { TATCCTG 3' } \\
\text { R: 5' GAAAACCCACT } \\
\text { TCTCCACCA 3' }\end{array}$ & $\begin{array}{l}35 \text { cycles }\left(45 \text { s } 95^{\circ} \mathrm{C}, 45\right. \\
\text { s } 58^{\circ} \mathrm{C}, 45 \text { s } 72^{\circ} \mathrm{C}, 10 \mathrm{~min} \\
\left.72^{\circ} \mathrm{C}\right)\end{array}$ \\
\hline GSR & $\begin{array}{l}\text { F: 5' CATCTATGCAGTT } \\
\text { GGGGATGT 3' } \\
\text { R: 5' TGAGTCCCACTGTC } \\
\text { CCAATAG 3' }\end{array}$ & $\begin{array}{l}35 \text { cycles }\left(45 \text { s } 95^{\circ} \mathrm{C}, 45\right. \\
\text { s } 58^{\circ} \mathrm{C}, 45 \text { s } 72^{\circ} \mathrm{C}, 10 \mathrm{~min} \\
\left.72^{\circ} \mathrm{C}\right)\end{array}$ \\
\hline VEGF & $\begin{array}{l}\text { F: 5' CCCACTGAGGAGTC } \\
\text { CAACAT 3' } \\
\text { R: 5' AAATGCTTTCTC } \\
\text { CGCTCTGA 3' }\end{array}$ & $\begin{array}{l}35 \text { cycles }\left(45 \text { s } 95^{\circ} \mathrm{C}, 45\right. \\
\text { s } 59^{\circ} \mathrm{C}, 45 \text { s } 72^{\circ} \mathrm{C}, 10 \mathrm{~min} \\
\left.72^{\circ} \mathrm{C}\right)\end{array}$ \\
\hline
\end{tabular}

fresh media and incubation continued for $72 \mathrm{~h}$. Negative control was set by addition of equal volume of the serum from confirmed HCV negative individuals.

RNA isolation and RT-PCR. At 72 hours post inoculation, cells were subjected to total cellular RNA extraction using TRIZOL reagent (Invitrogen, USA). RNA pellet was solubilized in DEPC (Sigma Aldrich) treated water and subjected to cDNA synthesis using specific antisense primer of HCV NS4A gene. Reaction conditions and PCR profile were optimized for selected genes for conventional PCR using 1-5 $\mu \mathrm{g}$ of cDNA. The PCR conditions of optimization are shown in Table 1 . Ten $\mu \mathrm{l}$ PCR products were mixed in $5 \mu \mathrm{l}$ of $6 \mathrm{x}$ loading dye were run in 2\% TAE agarose gel. Gel stained with ethidium bromide was visualized by Wealtec Dolphin Doc (Wealtec, USA) gel documentation system and specific band size was confirmed.

Real-time PCR. Reaction conditions and PCR profiles were optimized for all primers for real time PCR using $1 \mu \mathrm{g}$ of cDNA.
The reaction was carried out in 7300 Applied Biosystem Real time machine (Thermo Fisher, USA). The reaction was run at $95^{\circ} \mathrm{C}$ for $10 \mathrm{~min}$, and then 40 cycles at $95^{\circ} \mathrm{C}$ for $15 \mathrm{~s}, 60^{\circ} \mathrm{C}$ for $60 \mathrm{~s}$. Ct values of the target genes were compared to the reference housekeeping gene GAPDH and fold change in the expression of targeted markers was calculated. All statistical tests were carried out in Graphpad prism, version 5.0. The hypothesis was tested with student's t- test. ${ }^{\star} \mathrm{P}<0.05,{ }^{* *} \mathrm{P}<0.005,{ }^{* * *} \mathrm{P}<0.001$ was considered significant.

\section{Results}

\section{Huh-7 cell line infection}

In order to determine $\mathrm{HCV}$ induced oxidative stress and DNA damage, two Huh-7 cell lines were used (i.e. control and experimental). The control cell line (Huh-7/NR) was established by inoculating sera of healthy individuals with excellent health status. The healthy sera were screened against HCV and co-infection with HBV and HIV. Experimental cell line (Huh-7/HCV) was established by infecting with human HCV serum of genotype 3a. Cells were harvested $72 \mathrm{~h}$ post $\mathrm{HCV}$ inoculation and were processed for RNA extraction and subsequent cDNA synthesis. Five different sets of experiments were performed for establishment of $\mathrm{HCV}$ infectivity assays. Three out of five HCV infectivity assays were successfully confirmed by RT-PCR amplification of HCV non-structural protein NS4A using gene specific primer. No NS4A PCR amplification was observed in Huh-7/NR cells.

\section{Transcriptional analysis of oxidative stress markers}

For identification of signaling pathways involved in HCV induced oxidative stress distinct oxidant (COX-2) and antioxidant (GSR) were selected. The mRNA expression of GAPDH was used as internal control. The expression of selected genes was determined from three individual experiments with replicate samples from each study (Fig. 1).

COX-2 mRNA expression increased by 1.533 -fold in Huh-7/HCV as compared to Huh-7/NR at $72 \mathrm{~h}$ post inoculation with $\mathrm{P}$ value of 0.0119 ( $\mathrm{P}<0.05)$. The GSR m RNA expression also significantly increased by 1.27 -fold in Huh-7/ $\mathrm{HCV}$ as compared to Huh-7/NR at $72 \mathrm{~h}$ post inoculation with $\mathrm{P}$ value of $0.0392(\mathrm{P}<0.05)$. All values are presented as mean + SEM (Fig. 1).

$H C V$ induces DNA damage and repair by regulating ATM, ATR, DNAPKCs and PARP mediated signaling mechanism

For the identification of HCV induced DNA damage, mRNA transcripts of gene involved in DNA damage (ATM, 
ATR and DNAPKCs) and repair (PARP) were quantified in Huh-7/HCV and Huh-7/NR cells $72 \mathrm{~h}$ post inoculation by qRT-PCR. The mRNA expression of GAPDH was used as internal control (Fig. 2).

The expression of ATM mRNA level significantly increase by 1.27-fold in Huh-7/HCV as compared to Huh-7/NR at 72 $h$ post inoculation with $\mathrm{P}$ value of $0.0033(\mathrm{P}<0.01)$. The ATR expression also significantly increased by 1.1 -fold in Huh-7/ $\mathrm{HCV}$ as compared to Huh-7/NR at $72 \mathrm{~h}$ post inoculation with $\mathrm{P}$ value of $0.0303(\mathrm{P}<0.05)$. The expression of DNAPKCs was significantly increased in response to $\mathrm{HCV}$ infection. The DNAPKCs expression increased by 1.23 -fold in Huh-7/HCV as compared to Huh-7/NR at $72 \mathrm{~h}$ post inoculation with $\mathrm{P}$ value of $0.0011(\mathrm{P}<0.01)$. However insignificant decrease in expression of PARP with 0.6-fold was observed in Huh-7/ $\mathrm{HCV}$ in comparison to Huh-7/NR at $72 \mathrm{~h}$ post inoculation with $\mathrm{P}$ value of $0.5012(\mathrm{P}>0.05)$. All values are presented as mean + SEM. These expression studies were obtained from three individual studies with similar results (Fig. 2).

Role of tumor suppressor gene $R B$ and $P 53$ in response to DNA damage and repair

Genes of proteins P53 and RB are tumor suppressor genes involved in cell guard during stress conditions. To identify importance of these two genes in response to oxidative stress, DNA damage and repair, the mRNA transcripts of RB and P53 were quantified $72 \mathrm{~h}$ post inoculation in Huh-7/HCV and Huh-7/NR by qRT-PCR. The mRNA expression of GAPDH was used as internal control. The expression profiles were examined against 3 independent studies with replicate samples in each study (Fig. 3).

The Fig. 3 shows significant increase by 0.87 -fold in mRNA expression of RB in Huh-7/HCV as compared to Huh-7/NR at $72 \mathrm{~h}$ post inoculation with $\mathrm{P}$ value of $0.0026(\mathrm{P}<0.01)$. The $\mathrm{P} 53$ mRNA expression is also significantly increased by 0.93 -fold expression in Huh-7/HCV as compared to Huh-7/NR at $72 \mathrm{~h}$ post inoculation with $\mathrm{P}$ value of $0.0120(\mathrm{P}<0.05)$. All values are represented as mean + SEM (Fig. 3).

Transcriptional expression of vascular endothelial growth factor (VEGF) in response to $72 \mathrm{~h}$ post $\mathrm{HCV}$ inoculation in Huh-7 cell line

VEGF is potent marker of angiogenesis. During cancerous condition, the expression of VEGF is significantly increased. HCV causes hepatocellular carcinoma during chronic stage of viral infection. During tumor proliferation, the process of angiogenesis takes place. Transcriptional expression profile of VEGF after $72 \mathrm{~h}$ of HCV infection in Huh-7 cell line was determined for three separate samples in replicates for each sample. The mRNA expression of GAPDH was used as internal control.
mRNA expression levels of oxidative stress markers at 72 hours post HCV inoculation

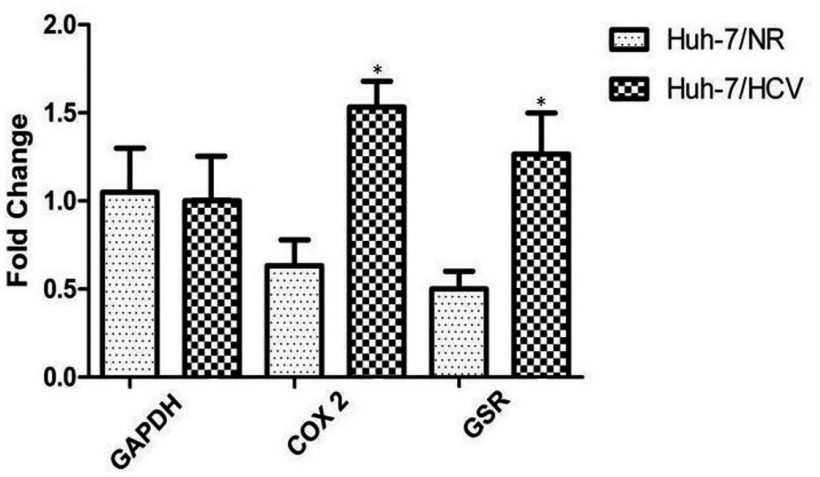

Fig. 1

Quantitative expression levels of COX-2 and GSR in Huh-7/NR and Huh-7/HCV cell lines at $72 \mathrm{~h}$ post inoculation

Both COX-2 and GSR mRNA expression levels significantly increased by 1.533- and 1.27-fold, in Huh-7/HCV as compared to Huh-7/NR at $72 \mathrm{~h}$ post inoculation with $\mathrm{P}$ value of 0.0119 and $0.0392(\mathrm{P}<0.05)$, respectively. All values are presented as mean $+\mathrm{SEM}$. These expression studies were obtained from three individual studies with similar results. ${ }^{\star} \mathrm{P}<0.05$.

mRNA expression levels of DNA damage and repair markers at 72 hours post $\mathrm{HCV}$ inoculation

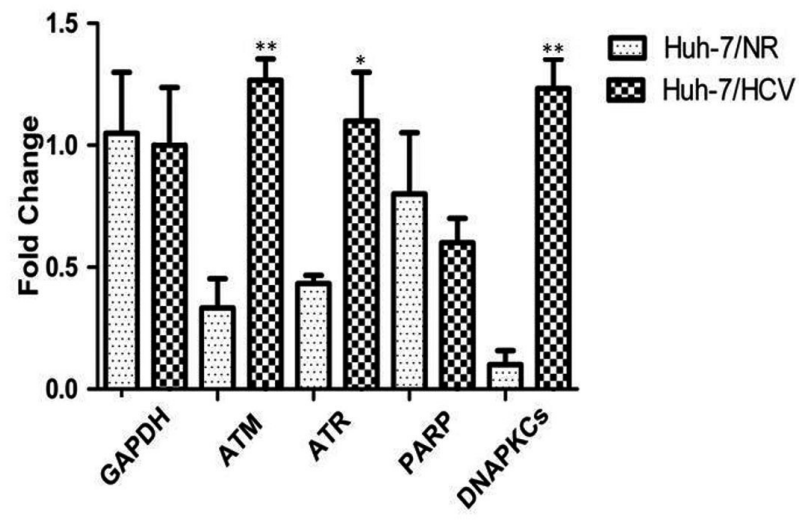

Fig. 2

Quantitative expression levels of ATM, ATR, DNAPKCs and PARP in Huh-7/NR and Huh-7/HCV cell lines at $72 \mathrm{~h}$ post inoculation mRNA expression levels of ATM, ATR and DNAPKCs significantly increased by 1.27 -fold, 1.1 -fold, and 1.23 -fold in Huh-7/HCV as compared to Huh-7/NR at $72 \mathrm{~h}$ post inoculation with $\mathrm{P}$ values of $0.0033(\mathrm{P}<0.01)$, $0.0303(\mathrm{P}<0.05)$ and $0.0011(\mathrm{P}<0.01)$, respectively. However, insignificant decrease in mRNA expression of PARP by 0.6 fold was observed in Huh-7/ $\mathrm{HCV}$ in comparison to Huh-7/NR on 72 hours post inoculation with $\mathrm{P}$ value of $0.5012(\mathrm{P}>0.05)$. All values are presented as mean + SEM. These expression studies were obtained from three individual studies with similar results. ${ }^{* *} \mathrm{P}<0.01,{ }^{*} \mathrm{P}<0.05$.

The figure 4 shows significant decrease by 0.367 -fold in expression of VEGF in Huh-7/HCV as compared to Huh-7/NR at $72 \mathrm{~h}$ post inoculation with $\mathrm{P}$ value of 0.0091 
mRNA expression levels of tumor suppressor gene markers at 72 hours post HCV inoculation

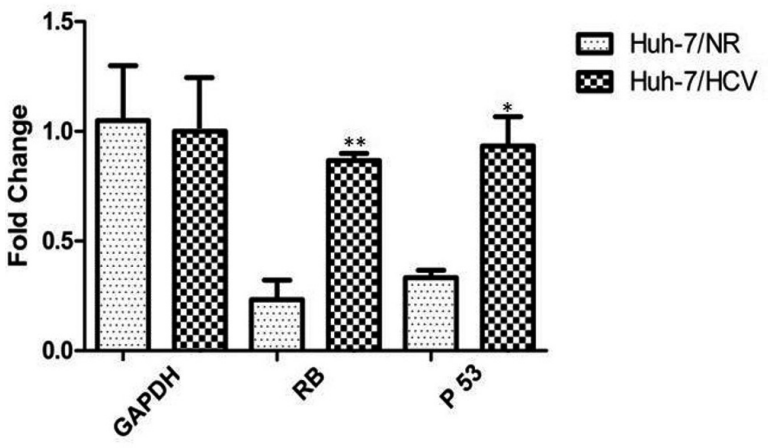

Fig. 3

Quantitative expression levels of RB and P53 in Huh-7/NR and Huh-7/HCV cell lines at $72 \mathrm{~h}$ post inoculation

mRNA expression level of both RB and P53 significantly increase by 0.87 -fold and 0.93 -fold in Huh-7/HCV as compared to Huh-7/NR at 72 $\mathrm{h}$ post inoculation with $\mathrm{P}$ value of $0.0026(\mathrm{P}<0.01)$ and $0.0120(\mathrm{P}<0.05)$, respectively. All values are presented as mean + SEM. These expression studies were obtained from three individual studies with similar results. ${ }^{*} \mathrm{P}<0.01,{ }^{*} \mathrm{P}<0.05$

\section{VEGF mRNA expression levels at 72 hours post HCV} inoculation

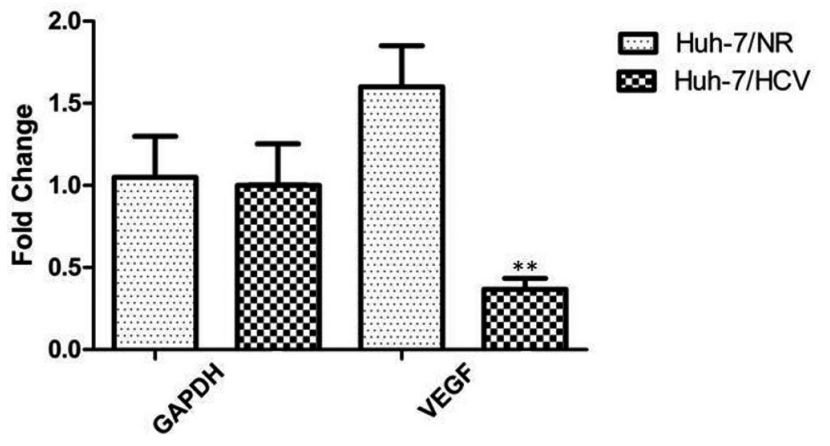

Fig. 4

Quantitative expression levels of VEGF in Huh-7/NR and Huh-7/HCV cell lines at $72 \mathrm{~h}$ post inoculation

mRNA expression level of VEGF significantly decreased by 0.367 -fold in Huh- $7 / \mathrm{HCV}$ as compared to Huh-7/NR at $72 \mathrm{~h}$ post inoculation with $\mathrm{P}$ value of $0.0091(\mathrm{P}<0.01)$. All values are presented as mean + SEM for both study groups. These expression studies were obtained from three individual studies with similar results. ${ }^{* *} \mathrm{P}<0.01$.

$(\mathrm{P}<0.01)$. All values are expressed as mean + SEM for both study groups (Fig. 4).

\section{Discussion}

HCV can itself directly induce oxidative stress in hepatocytes. HCV pathogenesis is predominantly thought to be imitative by the generation of ROS which would ultimately favor disease progression. ROS and resulting DNA damage complicate the progressing liver disease from acute to chronic infection and eventually towards HCC. Increased production of oxidants, results in elevated ROS and decrease of antioxidants aggravates DNA damage and HCC (Mahmood et al., 2004). ROS is considered to be major contributor in cytotoxic and pathophysiological pathways of liver pathogenesis. Cellular redox system is essentially required in equilibrium phase for a cell to perform normal functions. During viral infection the hepatocytes generate substantial amount of ROS causing imbalance in cellular redox system, influencing normal metabolic pathways thereby producing various cytokines, enzymes and transcription factors (Choi and $\mathrm{Ou}, 2006$ ).

The aim of our study was to design a preliminary study with establishment of HCV genotype 3 a infectivity assay in order to determine the DNA damage in Huh-7 cell line at $72 \mathrm{~h}$ post $\mathrm{HCV}$ inoculation. Initially it was hypothesized that after HCV infection the levels of oxidants would be significantly higher compared to antioxidants and the level of antioxidants would be significantly decreased. Due to oxidative stress the DNA damage would occur. For the detection of DNA damage the ATM, ATR and DNAPKCs transcriptional expression profile was evaluated compared with PARP gene involved in DNA repair mechanism. It was hypothesized that the level of ATM, ATR and DNAPKCs would be significantly higher and level of PARP would be decreased. If DNA damage is higher and DNA repair mechanism fails to counter, then the tumor suppressor genes P53 and $\mathrm{RB}$ might be unable to prevent the cell from entering mitosis phase and subsequently starting rampant proliferation. For the identification of cells in cancerous condition, the angiogenesis marker VEGF was selected.

Interestingly our findings revealed that after $72 \mathrm{~h}$ post HCV inoculation in Huh-7 cell lines, besides HCV induced oxidative stress and increased production of oxidants such as COX-2, the level of antioxidants such as GSR is also increased significantly. Despite of higher levels of oxidants and antioxidants, the cell undergoes DNA damage which was determined by higher levels of ATM, ATR and DNAPKCs. Our study revealed down regulation of DNA repair gene PARP, but this down regulation was statistically insignificant which might suggest that besides DNA damage and down regulation of DNA repair mechanism, the cell is also struggling to prevent cancerous condition by up regulating tumor suppressor genes (P53 and RB) which tends to down regulate VEGF expression. Our study revealed significant increase in transcriptional expression of tumor suppressor genes RB and P53 which confirms that hepatocytes tend to guard cell from cancerous condition. Previously, the role of RB with respect to $\mathrm{HCV}$ infection in hepatocytes was not determined. Our study for the first time shows that in presence of HCV 
infection the $\mathrm{RB}$ gene is also up regulated. In response to up regulation of $\mathrm{RB}$ and $\mathrm{P} 53$ the cells activate signaling pathways responsible for down regulation of VEGF which is involved in cancerogenesis. Thus cell prevents its entry into cancerous stage and cell cycle control occurs.

In our study COX-2 has been selected as marker of oxidants while GSR was selected as antioxidant marker. Usually in cell, the COX-2 is not constitutively expressed instead its expression is influenced by mitogenic stimuli and inflammatory responses. It has also been reported that COX-2 is induced by ROS and has strong correlation with inflammation and inhibition of apoptosis thus promoting carcinogenesis (Hla and Neilson 1992; Jones et al., 1993). Our study revealed that in Huh-7 cell line, at $72 \mathrm{~h}$ post $\mathrm{HCV}$ inoculation, the COX-2 expression increases by 1.533 -fold compared to normal Huh-7 cell line and shows that these cells are under oxidative stress. Rahman et al. (2001) and Tang et al. (2005) reported that COX-2 can induce angiogenesis by VEGF production and increase prostaglandin synthesis (Rahman et al., 2001; Tang et al., 2005). Seventy eight percent reduction in expression of VEGF level was observed in COX-2 siRNA treated Huh-7 cells, which shows strong association of COX-2 with VEGF (Zhou et al., 2001). But our study shows that in presence of significantly higher expression of COX-2 in Huh-7/HCV cell line at $72 \mathrm{~h}$ post inoculation, there was significant down regulation of VEGF and significantly increased expression of tumor suppressor genes P53 and RB. There is a possibility that the expression of VEGF would increases after several days post $\mathrm{HCV}$ inoculation when the levels of oxidants (such as COX-2) are significantly higher as compared to antioxidants (such as GSR) and cell looses cell cycle control thus becoming cancerous. It has been reported that the levels of $\mathrm{Zn}, \mathrm{Se}, \mathrm{Cu}$, oxidative stress and anti-oxidative enzymes have significant impact on viral factors in chronic patients with hepatitis $C$. The anti-oxidative enzymes including glutathione reductase (GSR/GR) and superoxide dismutase (SOD) are significantly increased in hepatitis $\mathrm{C}$ patients as compared to controls (Ko et al., 2005). The GSR is responsible for maintaining higher levels of reduced glutathione in cytosol, preventing oxidative stress and providing reducing environment to cell. A single nucleotide polymorphism (SNP) of GSR gene has been identified in African Americans which contributes to increased production of reactive oxygen production responsible for autoimmune disorder (lupus) in which antibodies produced in large scale are targeted against patients own DNA (Ramos et al., 2013). Our study revealed that at 72 $\mathrm{h}$ post HCV inoculation the level of GSR was significantly increased by 1.27 -fold expression.

The endogenous ROS causes damage to DNA on continuous basis due to which ROS can be stated as most important carcinogens. 8-hydroxy-7,8-dihydroguanine (8-OHGua) is involved in oxidative DNA damage. Severe oxidative stress has been associated with altered expression level of 8-OHGua in both the urine samples as well as in cellular DNA of patients which may lead to point mutations. The enzymes involved in DNA repair tends to recognize and specifically remove 8-OHGua, which depicts its significant role in DNA damage (Cheng et al., 1992). Wen et al. (2008) has also identified HCV induced DNA damage response dependent on ATM and ATR pathways (Wen et al., 2008). In presence of activated ATM and ATR DNA damage response, the HCV NS3/4A causes down regulation of NKG2D ligands (natural killer cell activating ligands). It has been reported that $\mathrm{HCV}$ NS3/4A interacts with ATM and tends to reduce efficiency of DNA repair mechanism. Similarly another study revealed that HCV core protein is also involved in activation of ATM and inhibits DNA repair enzymes to bind to damaged site by preventing formation of Mre11-NBS1-Rad50 complex (Lai et al., 2008; Machida et al., 2010). In our study significantly altered expressions of ATM, ATR and DNAPKCs were observed in experimental Huh- 7 cell line $72 \mathrm{~h}$ post $\mathrm{HCV}$ inoculation, proving thus DNA damage. In current study down regulation of PARP (DNA repair gene) was also observed and confirmed there is a molecular mechanism in presence of $\mathrm{HCV}$ at $72 \mathrm{~h}$ post inoculation which tends to down regulate the efficiency of DNA repair mechanism. Since altered expression of PARP in Huh-7/HCV cell line was insignificant thus it can be inferred that besides down regulation of PARP, the cell is also struggling to keep on producing PARP as the down regulation at $72 \mathrm{~h}$ is not significant. Ariumi and his colleagues showed that replication of genome length HCV RNA with genotype $1 \mathrm{~b}$ and subgenomic replicon RNA were significantly decreased in ATM and Chk2 knockdown 293FT cells. It was further reported that HCV NS3-NS4A tends to interact with ATM while HCV NS5B interacts with ATM and Chk2. This observation confirmed that ATM signaling pathway is essential for replication of HCV RNA. This finding is important for strengthening anti $\mathrm{HCV}$ defense strategies by designing potent inhibitors on the basis of in silico models for the treatment of chronic HCV patients (Ariumi et al., 2008).

Findings of our study are consistent with aforementioned study as the level of ATM was significantly increased by 1.27fold in presence of HCV. This suggests that higher expression of ATM correlates with successful virus replication, which was previously confirmed by PCR of HCV NS4A gene from serum infected Huh-7/HCV cell line. DNAPKCs are recently discovered sensor of DNA damage which plays crucial role in DNA damage. Very limited numbers of studies have been conducted to evaluate role of DNAPKCs in presence of $\mathrm{HCV}$ infection. Our study shows that at $72 \mathrm{~h}$ post inoculation, there occurs to be significant increase (1.23-fold) of transcriptional expression of DNAPKCs in Huh-7/HCV as compared to Huh-7/NR. In our study we had analysed major sensors of DNA damage (i.e. ATM, ATR and DNAPKCs) 
and potent marker of DNA repair (PARP). The levels of all selected DNA damage sensors have significantly increased, confirming DNA damage in HCV genotype 3 a infected cells at $72 \mathrm{~h}$ post inoculation. DNA repair gene PARP has shown mRNA expression down regulation by 0.6 fold in Huh-7/ HCV compared to Huh-7/NR. P53 is well known tumor suppressor gene involved in induction of cell survival as well as apoptosis pathways (Matoba et al., 2006; Murray-Zmijewski et al., 2008). Many studies have revealed that P53 is involved in selection of apoptosis or survival pathways inside the cell and generally regulated through intracellular ROS levels (Macip et al., 2003). Current study shows significantly increased mRNA expression of RB and P53 at $72 \mathrm{~h}$ post infection of HCV in Huh-7 cells. Previously the role of RB protein in presence of $\mathrm{HCV}$ infection was not identified. Our study has shown comparable significant increase of mRNA expression of both RB (0.87-fold) and P53 (0.93-fold) at 72 $\mathrm{h}$ post $\mathrm{HCV}$ inoculation in experimental cell lines. It has been reported that loss of P53 function or down regulation may contribute towards increased production of survival signals and rampant proliferation even in stress conditions by activating several downstream signaling molecules such as NFKB and VEGF (Sasaki, 2006). VEGF is potent marker of angiogenesis and development of cancerous stage. Current study shows significant down regulation of VEGF at $72 \mathrm{~h}$ post infection with decrease by 0.367 -fold in Huh- $7 /$ HCV as compared to Huh-7/NR. In accordance with aforementioned evidence it can be inferred that at $72 \mathrm{~h}$ of post $\mathrm{HCV}$ genotype $3 \mathrm{a}$ infection in Huh-7 cell lines, despite of significant DNA damage and inhibition of DNA repair, the cellular metabolism of P53 and RB is activated and guards the cell from cancerous transformation by inducing down regulation of VEGF. Our study is consistent with previous findings of our research group in which 96 and $144 \mathrm{~h}$ post inoculation in Huh-7/HCV cell line, the cells were protected from cancer transformation by induction of P53 mediated apoptosis.

$\mathrm{HCV}$ is responsible for causing infection in three percents of world's population. HCV infection promotes oxidative stress and has potential to cause damage to macromolecules. Our study is preliminary study conducted at $72 \mathrm{~h}$ post HCV inoculation. In the light of current study, HCV induced DNA damage and its role towards hepatocellular carcinoma can also be identified on stable cell lines for several days post $\mathrm{HCV}$ inoculation. The effect of different $\mathrm{HCV}$ genotypes and subtypes on DNA damage and their tendency towards HCC can also be determined on different liver cell lines such as novel human hepatocyte lines (HHLs) or hepatic stem cell line HepaRG and HepG2.

Acknowledgement. We are highly appreciative to National University of Sciences and Technology (NUST) Islamabad, Pakistan for their financial support.

\section{References}

Alter HJ, Holland PV, Morrow AG, Purcell RH, Feinstone SM, Moritsugu Y (1975): Clinical and serological analysis of transfusion-associated hepatitis. Lancet 2, 838-841. https://doi.org/10.1016/S0140-6736(75)90234-2

Ariumi Y, Kuroki M, Dansako H, Abe K, Ikeda M, Wakita T, Kato $\mathrm{N}$ (2008): The DNA damage sensors ataxia-telangiectasia mutated kinase and checkpoint kinase 2 are required for hepatitis C virus RNA replication. J. Virol. 82, 9639-9646. https://doi.org/10.1128/JVI.00351-08

Cheng KC, Cahill DS, Kasal H (1992): 8-Hydroxyguanine and abundant form of oxidative DNA damage causes G-T and A-C substitutions. J. Biol. Chem. 267, 166-172.

Choi J, Ou J (2006): Mechanisms of liver injury. III. Oxidative stress in the pathogenesis of hepatitis C virus. Am. J. PhysiolGastr. L. Physiol. 290, G847-851.

Feinstone SM, Kapikian AZ, Purcell RH, Alter HJ, Holland PV (1975): Transfusion-associated hepatitis not due to viral hepatitis type A or B. N. Engl. J. Med. 292, 767-770. https://doi.org/10.1056/NEJM197504102921502

Highleyman L (2008): Oxidative stress and the liver HCV advocate. Online available via: http://www.hcvadvocate.org/news/ newsLetter/2008/advocate0408.html\#3.

Hla T, Neilson K (1992): Human cyclooxygenase-2 cDNA. Proc. Natl. Acad. Sci. USA 89, 7384-7388. https://doi. org/10.1073/pnas.89.16.7384

Houghton M (2009): Discovery of the hepatitis C virus. Liver Int. 29, 82-88. https://doi.org/10.1111/j.1478-3231 .2008.01925.X

Jalal N, Haq S, Anwar N, Nazeer S, Saeed U (2014): Radiation induced bystander effect and DNA damage. J. Cancer Res.Ther. 10, 819-833. https://doi.org/10.4103/0973$\underline{1482.144587}$

Jones DA, Carlton DP, McIntyre TM, Zimmerman GA, Prescott SM (1993): Molecular cloning of human prostaglandin endoperoxide synthase type II and demonstration of expression in response to cytokines. J. Biol. Chem. 268, 9049-9054.

Ko WS, Guo CH, Yeh MS, Lin LY, Hsu GS, Chen PC, Luo MC, Lin CY (2005): Blood micronutrient, oxidative stress, and viral load in patients with chronic hepatitis C. World J. Gastroenterol. 14, 4697-4702. https://doi.org/10.3748/ wig.v11.i30.4697

Koike K (2007): Hepatitis C virus contributes to hepatocarcinogenesis by modulating metabolic and intracellular signaling pathways. J. .Gastroenter. Hepat. 22, S108-S111. https:// doi.org/10.1111/j.1440-1746.2006.04669.X

Lai CK, Jeng KS, Machida K, Cheng YS, Lai MM (2008): Hepatitis C virus NS3/4A protein interacts with ATM, impairs DNA repair and enhances sensitivity to ionizing radiation. Virology 370, 295-309. https://doi.org/10.1016/j. virol.2007.08.037

Machida K, McNamara G, Cheng KT, Huang J, Wang CH, Comai L, Ou JH, Lai MM (2010): Hepatitis C virus inhibits DNA damage repair through reactive oxygen and nitrogen species and by interfering with the ATM-NBS1/ 
Mre11/Rad50 DNA repair pathway in monocytes and hepatocytes. J. Immunol. 185, 6985-6998. https://doi. org/10.4049/jimmunol.1000618

Macip S, Igarashi M, Berggren P, Yu J, Lee SW, Aaronson SA (2003): Influence of induced reactive oxygen species in p53-mediated cell fate decisions. Mol. Cell. Biol. 23, 8576-8585. https://doi.org/10.1128/MCB.23.23.8576-8585.2003

Mahmood S, Kawanaka M, Kamei A, Izumi A, Nakata K, Niiyama G, Ikeda H, Hanano S, Suehiro M, Togawa K, Yamada G (2004): Immunohistochemical evaluation of oxidative stress markers in chronic hepatitis C. Antioixid. Redox. Signal. 6, 19-24. https://doi. org/10.1089/152308604771978318

Maki A, Kono H, Gupta M, Asakawa M, Suzuki T, Matsuda M, Fuji H, Rusyn I (2007): Predictive power of biomarkers of oxidative stress and inflammation in patients with hepatitis $\mathrm{C}$ virus associated hepatocellular carcinoma. Ann. Surg. Oncol. 14, 1182-1190. https://doi.org/10.1245/ s10434-006-9049-1

Mantena SK, King AL, Andringa KK, Eccleston HB, Bailey SM (2008): Mitochondrial dysfunction and oxidative stress in the pathogenesis of alcohol- and obesity-induced fatty liver diseases. Free Radic. Biol. Med. 1, 1259-1272. https:// doi.org/10.1016/j.freeradbiomed.2007.12.029

Matoba S, Kang JG, Patino WD, Wragg A, Boehm M, Gavrilova O, Hurley PJ, Bunz F, Hwang PM (2006): P53 regulates mitochondrial respiration. Science 312, 1650-1653. https://doi.org/10.1126/science.1126863

Murray-Zmijewski F, Slee EA, Lu X (2008): A complex barcode underlies the heterogeneous response of $\mathrm{p} 53$ to stress. Nat. Rev. Mol. Cell. Biol. 9, 702-712. https://doi.org/10.1038/ $\underline{\text { nrm2451 }}$

Rahman MA, Dhar DK, Yamaguchi E, Maruyama S, Sato T, Hayashi H, Ono T, Yamanoi A, Kohno H, Nagasue N (2001): Co-expression of inducible nitric oxide synthase and COX-2 in hepatocellular carcinoma and surrounding liver: possible involvement of COX-2 in the angiogenesis of hepatitis C virus positive cases. Clin. Cancer Res. 7, $1325-1332$.

Ramos PS, Oates JC, Kamen DL, Williams AH, Gaffney PM, Kelly JA, Kaufman KM, Kimberly RP, Niewold TB, Jacob CO, Tsao BP, Alarcón GS, Brown EE, Edberg JC, Petri MA, Ramsey-Goldman R, Reveille JD, Vilá LM, James JA, Guthridge JM, Merrill JT, Boackle SA, Freedman BI, Scofield RH, Stevens AM, Vyse TJ, Criswell LA, Moser
KL, Alarcón-Riquelme ME, Langefeld CD, Harley JB, Gilkeson GS (2013): Variable association of reactive intermediate genes with systemic lupus erythematosus in populations with different African ancestry. J. Rheumatol. 40, 842-849. https://doi.org/10.3899/jrheum.120989

Saeed U, Waheed Y, Ashraf M (2014): Hepatitis B and hepatitis C viruses: a review of viral genomes, viral induced host immune responses, genotypic distributions and worldwide epidemiology. Asian Pac. J. Trop. Dis. 4, 88-96. https:// doi.org/10.1016/s2222-1808(14)60322-4

Saeed U, Waheed Y, Ashraf M, Waheed U, Anjum S, Afzal MS (2015): Estimation of hepatitis B virus, hepatitis $C$ virus, and different clinical parameters in the thalassemic population of capital twin cities of Pakistan. Virology (Auckl) 6, 11-16.

Sasaki Y (2006): Does oxidative stress participate in the development of hepatocellular carcinoma? J. Gastroenterol. 41, 1135-1148. https://doi.org/10.1007/s00535-006-1982-z

Sies H (1997): Impaired endothelial and smooth muscle cell function in oxidative stress, oxidative stress: oxidants and antioxidants. Experitnental. Physiol. 82, 291-295. https:// doi.org/10.1113/expphysiol.1997.sp004024

Tang TC, Poon RT, Lau CP, Xie D, Fan ST (2005): Tumor cyclooxygenase-2 levels correlate with tumor invasiveness in human hepatocellular carcinoma. World J. Gastroenterol. 11, 1896-1902. https://doi.org/10.3748/wjg.v11.i13.1896

Vidali M, Tripodi MF, Ivaldi A, Zampino R, Occhino G, Restivo L, Sutti S, Marrone A, Ruggiero G, Albano E, Adinolfi LE (2008): Interplay between oxidative stress and hepatic steatosis in the progression of chronic hepatitis C. J. Hepatol. 48, 399-406. https://doi.org/10.1016/j. jhep.2007.10.011

Wen C, He X, Ma H, Hou N, Wei C, Song T, Zhang Y, Sun L, Ma Q, Zhong H (2008): Hepatitis C virus infection downregulates the ligands of the activating receptor NKG2D. Cell. Mol. Immunol. 5, 475-478. https://doi.org/10.1038/ cmi. 2008.60

World Health Organization, World Health Statistics Geneva (2008). Available online via: [http://www.who.int/gho/publications/world_health_statistics/EN_WHS08_Full.pdf.]

Zhou G, Myers R, Li Y, Chen Y, Shen X, Fenyk-Melody J, Wu M, Ventre J, Doebber T, Fujii N (2001): Role of AMP-activated protein kinase in mechanism of metformin action. J. Clin. Invest. 108, 1167-1174. https://doi.org/10.1172/ $\underline{\mathrm{LCI} 13505}$ 